\title{
AUTOMATION OF THE SHIPPING PROCESS OF METALLURGICAL PRODUCTS
}

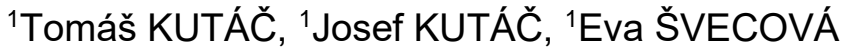 \\ ${ }^{1}$ VSB - Technical University of Ostrava, Ostrava, Czech Republic, EU, \\ josef.kutac@vsb.cz,tomas.kutac@vsb.cz, eva.svecova@vsb.cz
}

https://doi.org/10.37904/metal.2020.3639

\begin{abstract}
This article explores the options for automating the process involved in shipping metallurgical products. The shipping process usually begins with the logistics team entering a request for shipping into the information system after production is complete. The team then searches for a contracted transport company, selects the least expensive from the available options, creates an order in the system, contacts the selected company, and before commencing with shipment, enters the vehicle and driver information into the system. Under the desired solution, this entire process would be automated with a web application, with only the driver and vehicle information being entered by the transport company.
\end{abstract}

Keywords: Metallurgy, steel, logistics, dispatch, digitalization, automation, agile method

\section{INTRODUCTION}

Shipping products is an integral part of the logistics chain of every manufacturing company. The aim of shipping is to transport finished products to the customer according to a schedule in an arranged amount and quality [1]. In most cases, the manufacturing company uses an external companies for shipping, i.e. a carriers. The article examines optimization of the shipping process in which the metallurgical company wants to use several carriers and distribute shipments across these carriers effectively in order to minimize transportation costs and the time required to organize individual shipments.

\section{PROJECT}

\subsection{Project assumptions}

Each project can be grouped according to three basic stages:

- $\quad$ Pre-project stage (definition).

- $\quad$ Project stage (commencement, preparation, implementation, and completion).

- $\quad$ Post-project stage (evaluation, operation).

The purpose of the pre-project stage is to explore the project's opportunities and assess its feasibility. In this stage, analyses and studies are processed, for example, opportunity or feasibility studies. The purpose of this stage is to answer the most important questions and whether to go forward with the project.

The project stage involves preparation and planning of the project, official commencement, implementation and completion. The project's aims, team and schedule must be clearly defined from its start. As the project progresses, its results are compared with the established plan and correctional measures are applied.

The post-project stage evaluates the new expertise and experience acquired through the project and whether it can be applied in subsequent projects. The evaluation does not necessarily aim to seek accountability for any problems caused, but how to avoid the same mistakes in the future [2]. 


\subsection{Pre-project stage: Analysis of the current situation}

Experience shows that for a metallurgical company to optimize the shipping costs for its products while maintaining quality and schedule, cooperating with several carriers has benefits. These carriers may compete for individual shipping orders, and the company can select the best offer. In this case, the shipping costs reflect the current market conditions. Defining complex algorithms to update shipping costs, as it would be done with long-term and exclusive contracts with carriers, becomes unnecessary $[3,4]$.

However, preparing and planning shipping becomes a more demanding process. Each carrier needs to be approached separately, the best offer has to be selected, and the winning offer has to be confirmed with the carrier.

Such a process looks like this Figure 1:

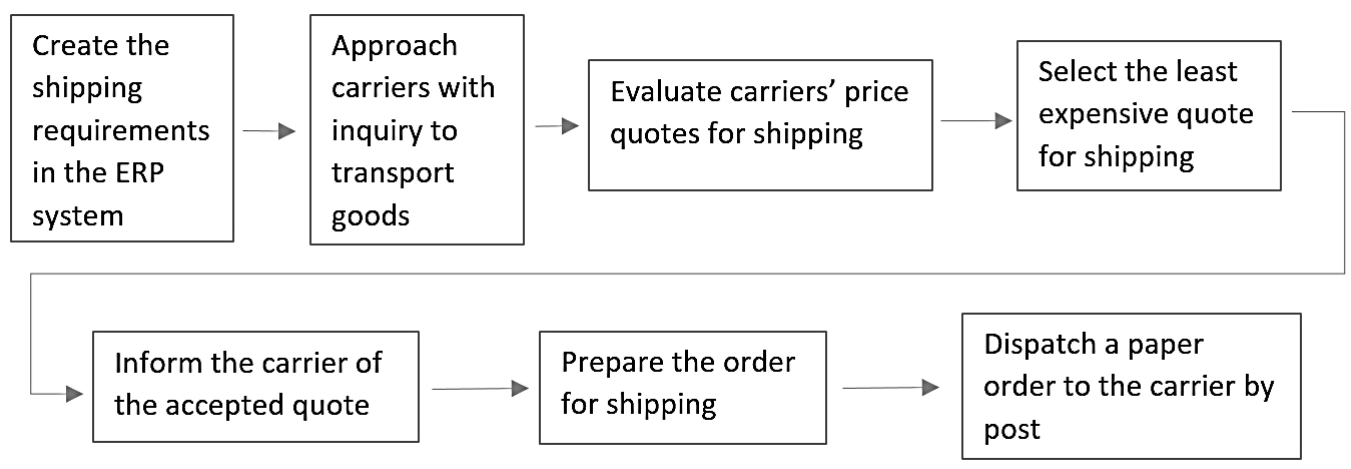

Figure 1 Process before automation

By default, all communication between the company and the carriers is done by e-mail. This entails a large number of e-mails which the logistics department must send and process. The entire process is therefore time consuming and there is the risk of an e-mail being overlooked and poor evaluation of a tender. The process is also very difficult to audit; finding specific information in the communications concerning a past shipment is complicated.

\section{Proposed new solution}

From the description above, it follows that the current process in planning shipments and selecting carriers entails many repeated and manual activities and that information about the progress of tenders is not sufficiently archived. The company's management clearly identified a need to digitize the entire process and automate repetitive activities.

The first option available at this company was use of the existing ERP system, in this case, SAP S/4 HANA. Analysis of this option revealed that using the SAP system to automate the shipping process was unsuitable, for the following reasons:

- $\quad$ Tendering was not a part of the already implemented logistics modules.

- $\quad$ The system was not economically beneficial in implementing the specialized module, as the company would only make use of a small part of it.

- $\quad$ A licence would need to be obtained for each carrier.

- A solution to access the SAP system outside the corporate network would be necessary.

A needs analysis incorporating the opportunities available to the company was used to create a proposal to develop a specialized web application for planning shipments. The main arguments of the solution were as follows: 
- $\quad$ The company had an experienced team of web application programmers at its disposal.

- $\quad$ The company has already successfully deployed and used web applications for other processes.

- The core of the already existing application could be used, requiring only the shipment planning process itself to be programmed.

The project goal received from management was, that after the first step when logistics department personnel will create the shipment in SAP containing the required information, the remaining part of process will be automated, and the web application would then be capable of sending all the required shipment information that carriers provide back into the SAP system.

The design of the digitized and automated process (in green - steps of the process covered by the new application) in Figure 2.

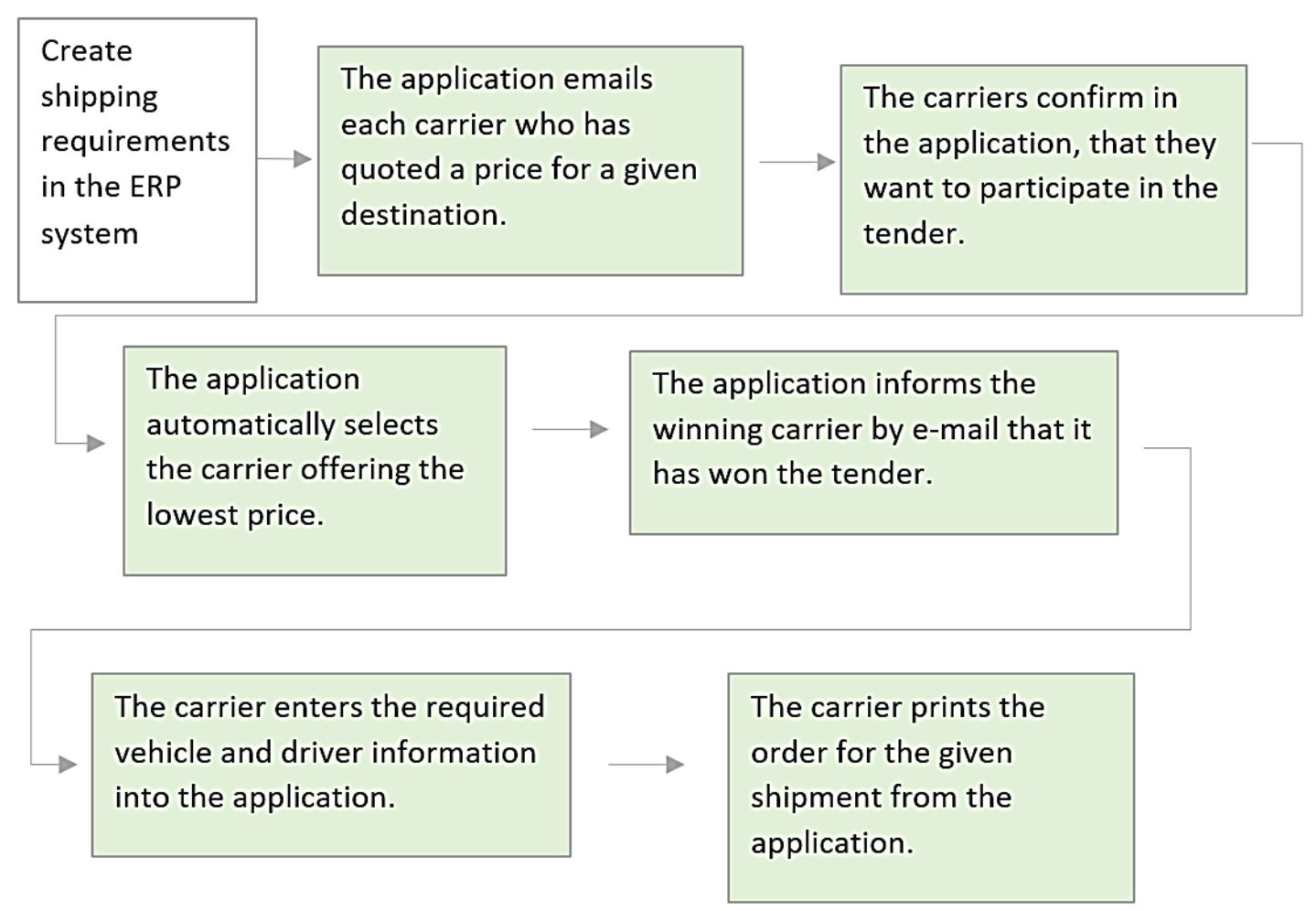

Figure 2 Process after automation

This proposal was submitted to the company's management, who approved it, and a project team and schedule were subsequently put together.

\subsection{Project stage: Implementation of the new solution}

Analysis of the most suitable solution indicated that the business team was not certain what this new process should look like. This was one reason modern agile methodology was applied to develop the application. The entire development process was broken down into smaller components. These parts were presented to users and could be modified according to their additional requirements.

Agile project management is an entirely new trend in managing projects and is currently preferred by many companies. To be agile means to be absolutely flexible towards the client, the solution team and other participants in the project and the progress of the project. It is important to understand that agility does not mean unlimited freedom. Even the most agile management system must have its clear rules. The border between agility and chaos is very thin in reality, therefore agility needs to be kept in check. 
Agile methodology stems from the effort to provide clients with partial outputs as soon as possible. These can be used for feedback to make required corrections in subsequent steps leading up to the final output. This approach is specifically presented as the agile methodology's key advantage. The waterfall approach and its effort to fixate on the goal right from the beginning of its life cycle of the project is deemed too rigid [5].

As expected, the application took two months to develop, one month being dedicated to user testing and tuning the process according to requirements. The assumption that the application according to the management's rough requirements would not be successfully developed into a fully functional output upon first attempt proved correct. This consideration in the plan allowed a realistic development schedule to be set.

\section{Testing and implementation}

Final testing experienced no major problems. Because testing was successful, management selected a date to launch the application. Following this decision, all users commenced training, carriers were informed of the impending changes, and training was also provided for their employees.

\subsection{The post-project stage}

After a month of use of the application, the new process was evaluated, and the time saved by logistics personnel was quantified. The compiled results showed that the new automated process helped reduce the time needed to plan shipments by over $50 \%$.

The commissioned project confirmed that the agile methodology was suitable and established it for use in future projects where the output would not possible to define at the outset of the project.

\section{CONCLUSION}

This case study examining automation of the process for shipping metallurgical products highlights several important points. Even traditional metallurgical companies can digitize and automate their processes. It does not necessarily need to concern main production, but savings in time can be achieved in the processes involved in shipping metallurgical products by digitalizing and automating the communications with the company's suppliers and clients. Another point is that incorporating all processes into the main ERP system is not always economically beneficial, and that developing a stand-alone application suitably integrated with existing systems can be cheaper and also more effective. The agile methodology was verified as a suitable approach for similar future projects since it allows the final output to be modified during project development and activities be incorporated into the schedule, and thus provides management with a realistic plan.

\section{ACKNOWLEDGEMENTS}

The work was supported by the specific university research of the Ministry of Education, Youth and Sports of the Czech Republic No. SP2020/60.

\section{REFERENCES}

[1] VANĚČEK, D. Logistika. České Budějovice: University of South Bohemia in Česke Budějovice, Faculty of Economics, 2008.

[2] DOLEŽAL, J., MÁCHAL, P., LACKO, B. Projektový management podle IPMA. Praha: Grada Publishing, 2012.

[3] JUROVÁ, M. Výrobní a logistické procesy v podnikání. Praha: Grada Publishing, 2016.

[4] WEELE, A.J. van. Purchasing and supply chain management. Seventh edition. Hampshire: Cengage, 2018.

[5] DVOŘÁK, D., MAREČEK, M. Project Portfolio Management. Brno: Computer Press, 2017. 